\title{
Cultural Translation of Idioms in Textbook Advanced English from the Perspective of Grammar
}

\author{
Xiaoyan Zheng \\ Kunming Railway Vocational and Technical College, Kunming 650208, Yunnan, China \\ Email: 378480992@qq.com
}

Abstract: For foreign language learners, there is a dead corner for them. Now that idioms may lead to a serious misunder-
standing, for they overload much information and background culture. Therefore, English idioms need specify the right
meanings of Chinese ones, which is essential for the second language learners to get a better understanding of the writer's
intention. This thesis adopts literature review and comparison analysis, and tends to explore the relationship between En-
glish idioms translation and Chinese ones in Advanced English complied by Zhang Hanxi, in order to find a better way of
relatively appropriate rending, in addition, to provide some suggestions for English language teachers in the teaching.
Keywords: equivalence translation, idioms, culture, cognition

\section{A selective overview of the textbook Advanced English}

Advanced English was the main course for advanced English majors, targeting at developing students' listening, speaking, reading and writing. It aims at helping students get a full preparation for a further study in linguistics, literature and translation. This book is popularized around china. there are more than 40 universities and collects and use it a reference book, including Zhejiang Normal University, Ningbo University, Shanxi Normal University, Zhengzhou foreign Language School etc. and this course is listed for the choosing course in some of the universities including Sichuan University of Science and Technology, Jiangxi Normal University, Nanjing aviation University, Inner Mongolian University, etc.

\section{Samples selected in Advanced English}

This thesis is also relevant to Advanced English complied by Zhang Hanxi. This book selected as a textbook is lying in following factors: firstly, it is popularized used in universities and colleges, so it has a widespread and significant influence around the whole china. Its target is English major students. More than 40 universities and colleges are using it as a text book. Besides, some of them explicitly point out that this book is the reference book for post graduates examination; therefore, some students esp., college students, consider it as a basic instrument for English learning, like listening, writing, and reading; some of them regard it as a device to learn more information about English, at same time, to develop their interest in English. What's more important, more and more students will learn this book or contact indirectly or indirectly. Secondly, its target is university students and post graduate students. So the content of the textbook is highly and closely focused. What kind of material is appropriate and how to arrange the content become big issues, attracting many experts' eyes. Thirdly, the compilation is authoritive and creative. Prof. Zhang is highly skilled in teaching, moreover, this book has been taught in universities and colleges more than once. It is not too difficult to find that Advance English contains a wide range of material: novel, drama, news, speech, and so on. Most of them are the original ones. Not only can reader enjoy different style of articles, but also different perspectives form different eras.

The idioms in the texts (because more or less, there are some ones missed) are selected out one lesson by one lesson, one idiom by one idiom.

All of the texts from Book I, consisting 16 articles, are selected from the original ones, some compressed or segmented. The style and content is so varied that student can contact different kinds of styles and broaden their horizon. Book II is the consecutive of Book I which consisting of 14 articles, but with more difficulty. It is adapted by appropriate length, standardized words. In the context, the author gives more detailed information in the notes and analysis.

Combined Book I and Book II, there are 3 narrations, 9 arguments, 6 prose, 5 novels, 1 drama, 3 illustrations and 2 speeches, more detailed information seen charpterII. There are 594 notes in total. There are 21 idioms in Book I and 40 idioms in Book II, 61 in total.

There are 3 narrations in Book1 and Book II and 4idioms in these three narrations; 9arguments in total and 30 idioms; 6 prose and 17 idioms in them; 5 novels and 4 idioms; 1 drama and 1idoms; 3 illustrations and 2 among them; and 2 speeches and 3 idioms in them, respectively. Among these styles, more idioms lie in arguments and prose, less in drama. 
According to statistic, in BookI idioms occupies 5.39\% of the whole expressions and notes, and in BookII, the ratio rises to $13.4 \%$.

Since this thesis is related to the translation theory, there is one problem that which kind of translation theory is more applicable, in terms of the article style. To solve the problem, Nida's ET (equivalence translation) theory is quoted, since Newmark's translation standard focuses on different styles, and Yan Fu intends to emphasize the fluent and smooth way of rendering the original in the TL on the basis of a comprehensive understanding of the original. However, there are some commons among these three principles.

\section{Equivalence Translation of Idioms in Advanced English}

\subsection{From the perspective of grammar}

\subsubsection{The forward-transformation}

Idioms are typically constructed on quite normal grammatical patterns of phrase structure, but the meaning of the whole idiom is not simply the sum of the meanings of the parts, nor can one segment the meaning (in the many cases where it is complex), assign a definable potion of the meaning to each grammatical piece (Here refers to a morpheme), either.

(1) Those which all the essential components of both kernels remain explicitly and overtly expressed. Here are some examples selected from the textbooks:

a. cater to ... (lesson 8, BookI) 一 投其所好

b. churn out (lesson 13, Book I) 一大量生产

c. sit out (lesson 1, Book II) 一坐到结束

Firstly, the kernels in each idiom should be picked out. The kernel words in a. "cater" which means to satisfy somebody's need (OALD, 2002: 213); b. "churn" which means to produce (OALD, 2002: 240); c. "sit" which means to stay in a position in which the body is upright and resting on the buttocks, either on a seat or on the ground (OALD, 2002: 1415); These kernels can find their Chinese corresponding meanings. The kernels in Chinese ones are respectively: a. 迎合; b. 生产; c. 坐. Comparing the two corresponding patterns, meaning loss remain almost the same from English idioms translation to Chinese ones if kernels remain explicitly and overtly expressed.

(2) Those in which some of the elements of at least one of the kernels are left implicit or covert. And in English, there are three types of combinations which retain in the surface structure all of the elements of the kernels.

(a) Those in which the relation between the two kernels are marked by a conjunction, since the premise is that the idiom is a sentence or word patterns, this model is seldom seen in Advanced English concerning the idioms. Here are some examples:

neither flesh, fowl, nor good salt herring (lesson 12, Book I) — 四不像

Here is a negative pattern "neither...nor..."connected with three objects "flesh, fowl, and herring (herring: Atlantic fish, usually swimming in very large shoals, used for food.)"

However, in china, “四不像” is kind of animal, referring to a kind of deer一麇鹿. It belongs to cervical. Neck, back and limbs are relatively thick. Leniency can be separated from the main hoof; here is membrane among soles with developing side hoof. And it is habituated in swamp, summer fur reddish brown, there is less similar for both of them from their two original meanings. There is an ocean difference between Chinese original meaning and English original meaning. Flesh, fowl and herring have nothing to do with Chinese “四不像”. However, in a indicate sense, both of them can refer to something odd.

(b) those in which the relation of one kernel to a part of another is marked by a relative pronoun. Here are some examples. Among the following example, pronoun involved in idioms:

a. it doesn't matter twopence (lesson 2, Book II) 一无关紧要

b. nothing upstairs (lesson 5 , Book II) 一 没头没脑

c. keep up with the Joneses (lesson 8, Book II) 一 与他人攀比

Here, a. "it" is an unreliable noun as a colloquial word. It has no definite meaning here. In a superficial sense, since there is "twopence" following after "it", "it" may refer to certain products or goods. In Chinese meaning, "it" refers to something instead of certain products or goods. b. "nothing" is a indicator pronoun, referring to a negative sense. In Chinese meaning, it is narrowed down to part of body, "head" and "brain" involved. Meaning happens to change somewhere. c. "the Joneses" indicates very rich person. These functions are very popular in English idioms, e.g., "Uncle Tom" referring to the Negroes.

(c) those in which one of the kernels has been transformed into a "dependent" form without a connective marker. Here are some examples:

a. all over (lesson 9, Book I) 一一模一样

b. I don’t give you a shit. (Lesson 12, Book I) 一 我对此漠不关心 
c. feel the pinch (Lesson 13, Book I) 一 开始缺钱了

In this model, English idioms could not be segmented. For the pattern, "all over" cannot be separated to "all" or "over"; "write off" cannot be separated to "write" or "off". Neither can the phrases and sentences.

In other words, expressions in which the semantic and grammatical structure are radically different. Hence it is idle to attempt to determine the "meaningful relation of the parts"; one must treat the entire expression as a semantic unit, even though I the surface structure of the grammar it obeys all of the rules applicable to the individual piece.

\subsubsection{Back-transformation}

Back-transformation of a surface structure to the underlying kernels may be regarded as a form of paraphrase, and it is pertinent to ask in what respects this kind of paraphrase differs from certain other kind. The word "paraphrase" has sometimes been used to mean a quite loose and inaccurate translation, in which the translator has injected uncontrolled subjective judgments and thus biased to the result. Look at the following examples:

a. rub shoulders with (Lesson 2, Book I) 一摩肩擦踵

b. throw in the towel (Lesson 13, Book I) 一退出竞争

c. of sorts (Lesson 9, Book I) 一勉强算得上

d. stand in a way (Lesson 16, Book I) 一妨碍

a. "rub shoulders with", the message the author to say that there is a lot of people, but the original meaning in Oxford dictionary: meet somebody officially or professionally (ibi: 1312), there is a great change in this idiom. And the Chinese one : 摩肩擦踵. This is a paralleling structure but decodes the same meaning; "rub the shoulders and heels", according to different cultures, something added here but it's permitted.

b. "throw in the towel": Chinese translation is creatively changed.. This one applied certain figure of speech: metaphor. In the war, the loser part usually show the white flag or towel to commit a failure, it is the same as Chinese saying : 举白旗 投降. But in Chinese, the towel doesn't work this meaning.

In summary, to state the relationships between words in order to get least ambiguous, expressions are recast so that events are expressed as verbs, objects as nouns, abstracts (quantities and qualities) as adjectives or adverbs.

There restructured expressions are basically what many linguists call "kernels"; that is to say, there are the basic structural elements out of which the language builds its elaborate surface structures. In fact, one of the most important insights coming from "transformational grammar" is the structures out of which all the more elaborate formations are constructed by means of so-called "transformations". In contrast, back-transformation, then, is the analytic process of reducing the surface structure to its underlying kernels. From the standpoint of the translator, however, what is even ore important than the existence of kernels in all languages is the fact that languages agree far more on the level of the kernels than on the level of the more elaborate structures. This means that if one can reduce grammatical structures to the kernel level, they can be transferred more grammatical structures to the kernel level, they can be transferred more readily and with a minimum of distortion. The kernel expressions themselves are not to be translated literally.

\section{Conclusion}

English idioms in Advanced English are analyzed through three perspectives: from perspective of grammar analysis, each idiom holds a kernel, which is the core of meaning. Meanwhile, kernel determines stylistic features of the source language, connotative included; from perspective of structure, during the process of translation from English idioms into Chinese ones, figurative meaning of individual words, shifts and context should be emphasized; from perspective of communication, SL and TL are bridged both by media agent and translators perception, which has been always overlooked.

\section{References}

[1] Paul Procter. Cambridge International Dictionary of Idioms. Shanghai: Shanghai Foreign Language Press;1999.

[2] Claire Kramsch. Context and Culture in Language Teaching. Shanghai: Shanghai Foreign Language Press; 1999.

[3] Eugene A. Nida, Charlers R. Taber. The Theory and Practice of Translation. Shanghai: Shanghai Foreign Language Press; 2004.

[4] Eugene A. Nida. Language and Culture Contexts in Translation. Shanghai: Shanghai Foreign Language Press; 2001.

[5] Larry A. Samovar \& Richard E. Porter. Communication Between Cultures (fifth edition). Beijing: Peking University Press; 2004.

[6] Myron W. Lustig \& Jolene Koester. Intercultural Competence: Interpersonal communication Across Culture (fifth edition). Shanghai: Shanghai Foreign Language Press; 2007. 
[7] Simpson, John A. The Oxford English Dictionary (II). Oxford: Clarendon Press; 1989.

[8] Xu Xiaodan. Culture Translation in Idioms. Academic Exchange. 2014; (05).

[9] Song Zhiga. Image and Meaning in Idioms Translation. Academic Journal of South China University of Technology (Natureal Science Edition). 1997; (S2).

[10] Du Juan. English Translation for Chinese Idioms from Perspective of Culture Translation. Academic Journal of Shenyang Agriculture University (Social Science Edition). 2010; (01).

[11] Dong Jing. English Translation for Chinese Idioms from Perspective of Equivalence Translation. Academic Journal of Changchun University of Technology (Social Science Edition). 2016; (02). 